\title{
PERANCANGAN CAKUPAN AREA LONG TERM EVOLUTION (LTE) DI DAERAH BANYUMAS
}

\author{
Alfin Hikmaturokhman ${ }^{1}$, Anggun Fitrian Isnawati ${ }^{2}$, Upit Herlina ${ }^{3}$ \\ Program Studi D-III Teknik Telekomunikasi \\ Akademi Teknik Telkom Sandhy Putra Purwokerto \\ alfin@akatelsp.ac.id, anggun_fitrian@yahoo.com, upit.herlina@gmail.com
}

\begin{abstract}
ABSTRAK
Seiring dengan perkembangan teknologi yang pesat di seluruh bidang teknologi tak terkecuali dengan teknologi telekomunikasi. Semakin banyak pula fasilitas yang ditawarkan, contohnya adalah perkembangan telekomunikasi untuk layanan voice, data maupun video. Tentunya penawaran tersebut harus ditunjang oleh teknologi yang mampu menopangnya, yaitu dengan kemampuan memiliki kecepatan transfer data rate yang tinggi. Salah satu teknologi yang mampu menjawab kebutuhan tersebut adalah teknologi LTE. LTE sendiri dikembangkan dari teknologi Global System for Mobile (GSM) dan Universal Mobile Telecommunication System (UMTS) dan merupakan teknologi yang memiliki kecepatan data rate hingga 100 Mbps untuk arah downlink dan 50 Mbps untuk arah uplink. Karena pemerataan kemajuan teknologi di berbagai daerah termasuk daerah Banyumas, maka diperlukan sebuah penerapan teknologi LTE di daerah tersebut. Penerapan ini tidak akan berjalan tanpa adanya perencanaan yang baik mengenai suatu jaringan LTE untuk dapat mencakup seluruh area Banyumas. Agar penerapan LTE di daerah Banyumas dapat optimal maka diperlukan perancangan cakupan area LTE, link budget dan jumlah eNode B yang dibutuhkan. Dengan menggunakan modulasi QPSK dan coding rate 1/2 menghasilkan nilai kapasitas trafik sebesar 3.344,096 kbps/km2. Jumlah eNode B yang dapat mencakup seluruh area Banyumas adalah sebanyak 59 eNode B. Pengaruh besar nilai coding rate terhadap MAPL yaitu semakin besar nilai coding rate maka menghasilkan nilai MAPL yang semakin kecil dan jumlah eNode B yang semakin banyak.
\end{abstract}

Kata Kunci : LTE, Banyumas, link budget, jumlah eNode B.

\begin{abstract}
Along with the rapid technological developments in all fields of technology, it's including telecommunications technology. Many facilities are offered, for example, is the development of telecommunications services for voice, data and video. This offer must be supported by great technology, which is ability transfer data with high speed transfer data rate. The technology that able to grant this needs is LTE technology. LTE technology was developed from Global System for Mobile (GSM) and Universal Mobile Telecommunication System (UMTS) and this technology has transfer data rate up to 100 Mbps for the downlink and 50 Mbps for the uplink direction. Because the distribution of technological progress in various areas including Banyumas, it would require an application of LTE technology in that area. These applications will not run without proper planning of an LTE network to cover all areas of Banyumas. In order to apply the optimal LTE network in Banyumas it is necessary to design LTE coverage area, they consist of link budget and number of eNode B that required to cover whole area Banyumas. By using QPSK modulation and coding rate $1 / 2$ it has value traffic capacity about 3.344,096 kbps/ $/ \mathrm{km} 2$. ENode B number that can cover whole area is as much as 59 eNode B. Impact of coding rate to MAPLvalue is when value of the coding rate is greater it's produces a smaller value of MAPL and the number of eNode B is increase.
\end{abstract}

Keyword : LTE, Banyumas, link budget, number of eNode B

\section{PENDAHULUAN}

\subsection{Latar Belakang}

Seiring dengan perkembangan teknologi yang pesat di seluruh Indonesia termasuk daerah Banyumas, teknologi pada bidang telekomunikasi juga berkembang dengan pesat yang ditandai dengan semakin banyaknya fasilitas yang ditawarkan, contohnya adalah perkembangan komunikasi data dan voice. Komunikasi data yaitu pertukaran data dari 
satu tempat ke tempat yang lain melalui jaringan. Sedangkan komunikasi voice sendiri prinsipnya sama dengan komunikasi data, hanya saja yang dikirimkan berupa voice. Semakin sibuk kegiatan manusia untuk melakukan pertukaran data dan voice maka dibutuhkan sebuah teknologi terkini untuk melakukan hal tersebut, karena alasan ini maka bidang telekomunikasi menjadi salah satu bidang yang memiliki peranan penting dalam kehidupan masyarakat.

Teknologi yang dapat memenuhi tuntutan komunikasi data dan voice tersebut salah satunya adalah teknologi Long Term Evolution (LTE), dimana LTE merupakan teknologi yang terstandarisasi oleh teknologi $3^{\text {rd }}$ Generation Partnership Project (3GPP). LTE dirancang untuk menyediakan efisiensi spektrum yang lebih baik, peningkatan kapasitas radio, biaya operasional yang lebih murah bagi operator, serta layanan mobile broadband dengan kualitas tinggi untuk pengguna. LTE sendiri dikembangkan dari teknologi Global System for Mobile (GSM) dan Universal Mobile Telecommunication System (UMTS), dengan teknologi ini kecepatan data rate yang dikirimkan meningkat. Untuk mendukung fasilitas LTE yang baik diperlukan juga perancangan jaringan LTE yang baik, sehingga semua User Equipment dapat menerima sinyal dengan baik untuk dapat menikmati kecepatan pengiriman data yang tinggi.

Karena pemerataan kemajuan teknologi di berbagai daerah termasuk daerah Banyumas, maka diperlukan sebuah penerapan teknologi LTE yang merupakan teknologi terbaru yang dapat memenuhi tuntutan komunikasi data dan voice di daerah tersebut. Untuk mendukung pemerataan kemajuan teknologi di daerah Banyumas maka diperlukan suatu perencanaan suatu jaringan LTE yang baik dan dapat mencakup seluruh daerah Banyumas. Agar penerapan LTE di daerah Banyumas dapat optimal maka diperlukan perancangan cakupan area LTE serta link budget-nya. Dalam perancangan link budget akan dihitung loss total, jangkauan eNode $B$, luas daerah yang dapat dicakup oleh satu eNode $B$, serta menentukan jumlah eNode $B$ yang dibutuhkan.

\subsection{Rumusan Masalah}

Berdasarkan uraian diatas terdapat masalah yang perlu dikaji lebih lanjut yaitu:

1. Bagaimana perhitungan link budget pada transmisi LTE, yang berupa up link dan down link?

2. Bagaimana memperhitungkan kapasitas jaringan LTE?

\subsection{Tujuan Penulisan}

Adapun beberapa tujuan dari pengambilan judul ini adalah seperti berikut ini:

1. Mampu memperhitungkan link budget pada transmisi LTE pada perancangan cakupan area LTE di daerah Banyumas.

2. Mampu memperhitungkan kapasistas jaringan LTE.

\subsection{Batasan Masalah}

Sejumlah permasalahan yang dibahas dalam penelitian ini akan dibatasi ruang lingkup pembahasannya:

1. Hanya membahas mengenai cakupan area LTE di daerah Banyumas. 
2. Memperhitungkan link budget untuk up link dan down link pada kapasitas jaringan LTE.

3. Frekuensi yang digunakan untuk pengoperasian LTE adalah $900 \mathrm{MHz}$ dan $1800 \mathrm{MHz}$.

\section{METODOLOGI PENELITIAN}

Metodologi yang ditempuh dalam menyelesaikan penelitian ini meliputi studi literatur dan pembuatan simulasi menggunakan instrumen berupa software Matrix Laboratory (MATLAB). Pada penelitian ini akan diamati beberapa parameter yang berpengaruh pada hasil simulasi, diantaranya adalah prediksi jumlah pelanggan, Luas area perencanaan, Maximum Allowable Path Loss (MAPL), Offered Bit Quantity (OBQ), Jumlah eNode B, Luas cakupan, Sensitivity Receiver, Jumlah daya yang dipancarkan, Model Propagasi. Untuk metode pengumpulan data menggunakan metode observasi atau pengamatan, yaitu mengamati hasil perhitungan atau simulasi yang ada. Sedangkan metode analisa yang digunakan adalah analisa komparasi dari perhitungan yang telah dilakukan.

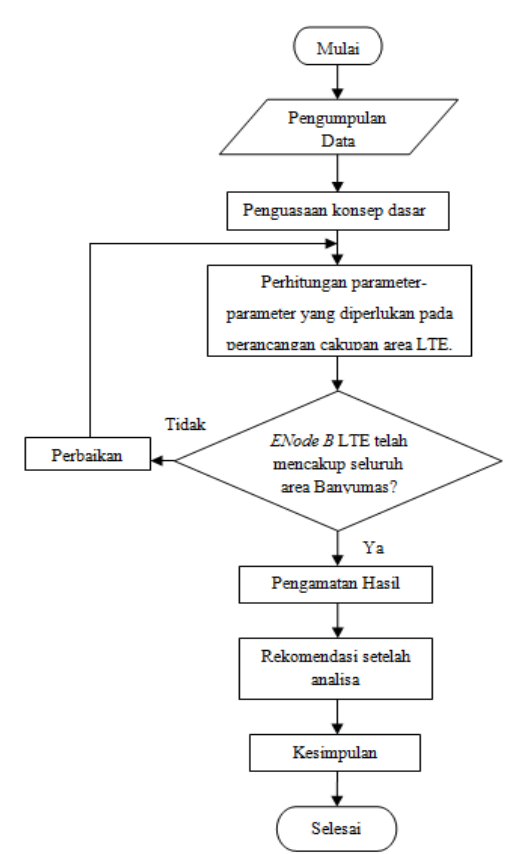

Gambar 1. Flowchart penelitian

\section{PERANCANGAN SISTEM}

\subsection{Pemodelan Rancangan}

Perancangan yang akan menghasilkan output berupa jumlah eNode $B$ untuk mencakup seluruh daerah Banyumas dan angka kapasitas dari jaringan dan sel LTE. Berikut diagram alir untuk perancangan cakupan area LTE:

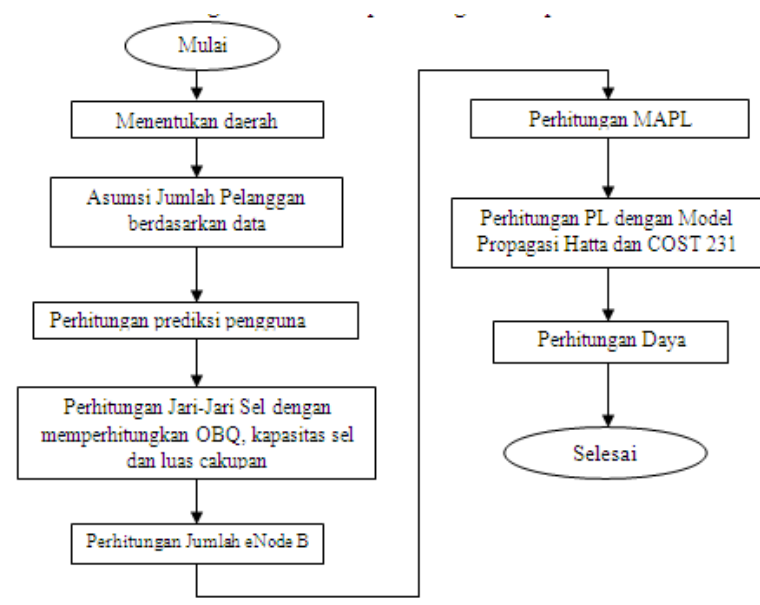

Gambar 2. Flowchart Perancangan Cakupan Area LTE

\subsection{Survey Daerah Kabupaten Banyumas}

Berdasarkan survey site, kabupaten

Banyumas memiliki daerah pada peta seperti berikut: 


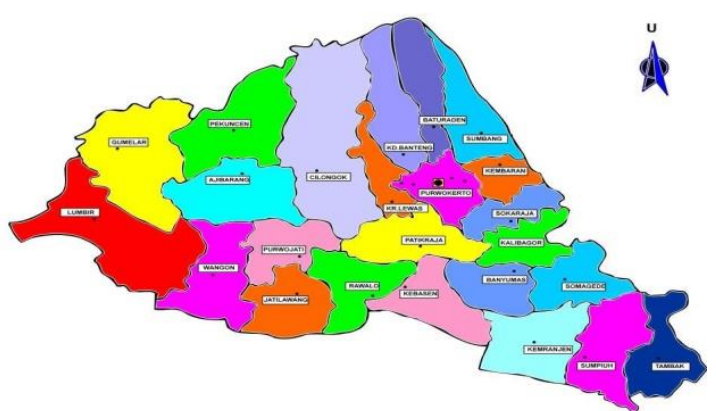

Gambar 3. Peta Kabupaten Banyumas

\subsection{Perencanaan Long Term Evolution (LTE)}

a. Capacity Planning

Perancangan dimulai dengan perhitungan jumlah pelanggan, dan diikuti dengan perhitungan OBQ dan perhitungan kapasitas sel.

- Perhitungan Jumlah Pelanggan

Perhitungan untuk jumlah pelanggan menggunakan persamaan seperti berikut:

$U_{n}=U_{o}\left(1+f_{p}\right)^{n}$

- Perhitungan OBQ

Perhitungan Offered Bit Quantity (OBQ) dengan menggunakan persamaan rumus berikut:

$O B Q=c \times \sigma \times p \times d \times B H C A \times B W$

- Perhitungan Kapasitas Sel (C)

Persamaan untuk menghitung kapasitas sel adalah dengan menggunakan persamaan berikut:

$$
C=B * \log _{2}(1+S N R)
$$

b. Coverage Planning

- Perhitungan Luas Cakupan

Untuk menghitung luas cakupan dengan menggunakan tiga sektor, digunakan rumus seperti berikut:

$L=($ kapasitas sel $\times 3) / O B Q t o t a l(4)$
- Perhitungan Jari-Jari Sel

Jari-jari sel diperhitungkan untuk mendapatkan nilai banyaknya jumlah eNode $B$ yang diperlukan untuk mencakup seluruh area Banyumas, adapun persamaannya adalah:

$d=\sqrt{\frac{L}{2,6 \times 1,95}}$

- Perhitungan Jumlah eNode B

Perhitungan jumlah eNode $B$ dihitung dengan menggunakan persamaan berikut:

Jumlah eNode $B=$

Luas area perencanaan Luas cakupan sel

- Radio Link Budget

Perhitungan radio link budget ini digunakan untuk mengetahui estimasi nilai maksimum dari pelemahan sinyal yang diperbolehkan antara UE (User Equipment) dengan eNode $B$, nilai pelemahan sering disebut dengan Maximum Allowable Path Loss (MAPL). Untuk menghitung MAPL (Maximum Allowable Pathloss) arah downlink diperlukan perhitungan parameter-parameter berikut:

a) Perhitungan parameter EIRP

$\mathrm{EIRP}=\mathrm{Ptx}+\mathrm{Gtx}-$ Loss system

b) Perhitungan parameter Sensitivity Receiver (SR)

$S R=k T B+N F+S I N R$

- $k T B=10 \log \left(1,38 \times 10^{-23} \times\right.$ $\left.290 \times 13,5 \times 10^{6}\right)$

- $\quad k T B=-132,674 d B+30$

- $k T B=-102,674 \mathrm{dBm}$ 
c. Perhitungan MAPL arah downlink

MAPL =

EIRP - SR - IM -

control chanel overhead +

Grx - body loss

Sama halnya dengan perhitungan MAPL untuk arah downlink, para arah uplink juga diperlukan parameter-parameter berikut:

a) Perhitungan parameter EIRP

$\mathrm{EIRP}=\mathrm{Ptx}+\mathrm{Gtx}-$ body loss

b) Perhitungan MAPL

$\mathrm{MAPL}=\mathrm{EIRP}-\mathrm{SR}-\mathrm{IM}-$

MHA gain - cable loss + Grx

d. Model Propagasi

Model propagasi digunakan untuk memodelkan kanal, berikut model propagasi yang digunakan:

a) Model Propagasi Okumura-Hatta

Model propagasi ini menggunakan

frekuensi perencanaan $900 \mathrm{MHz}$, persamaan rumusnya seperti berikut:

$L_{\text {suburban }}=69,55+26,16 \log f-$

$$
\begin{aligned}
& 13,82 \log h_{t e}-a_{h r e}+ \\
& \left(44,9-6,55 \log h_{t e}\right) \log d- \\
& 2[\log (f c / 28)]^{2}-5,4 \ldots \ldots \ldots . .(12
\end{aligned}
$$

b) Model Propagasi COST 231

Model propagasi COST 231 pada perencanaan frekuensi $1800 \mathrm{MHz}$, persamaannya seperti berikut:

$$
\begin{aligned}
& L_{\text {urban }}=46,3+33,9 \log f_{c}- \\
& 13,82 \log h_{t e}-a\left(h_{r e}\right)+(44,9- \\
& \text { 6,55 } \left.\log h_{t e}\right) \log _{10} d+C M
\end{aligned}
$$

e. Daya Terima User Equipment

Daya terima UE dapat diprediksi untuk mengetahui besar daya sinyal yang diharapkan diterima oleh UE, daya terima UE ini sering disebut dengan Receive Signal Level (RSL), dapat dihitung dengan persamaan berikut:

$R S L(d B m)=P t+G t+G r-P L$

IV. ANALISA HASIL PERHITUNGAN \& HASIL SIMULASI

\section{Hasil Perhitungan OBQ}

Data pada tabel 4.1 tersebut dihasilkan pada perhitungan dengan menggunakan persamaan 2.

Tabel 4.1. OBQ total

\begin{tabular}{|c|c|c|c|}
\hline \multicolumn{4}{|c|}{ OBQ } \\
\hline $\begin{array}{c}\text { Servic } \\
e\end{array}$ & Building & $\begin{array}{c}\text { Pedestria } \\
n\end{array}$ & $\begin{array}{c}\text { Vehicul } \\
\text { ar }\end{array}$ \\
\hline Voip & 107,52 & 43,008 & 29,03 \\
\hline Video & 225,792 & 129,024 & 116,122 \\
\hline FTP & 1.260 & 627,2 & 806,4 \\
\hline $\begin{array}{c}\text { Jumla } \\
\text { h }\end{array}$ & $\begin{array}{c}1.593,31 \\
2\end{array}$ & 799,232 & 951,552 \\
\hline $\begin{array}{c}\text { OBQ } \\
\text { total }\end{array}$ & \multicolumn{3}{|c|}{$3.344,096$} \\
\hline
\end{tabular}

\section{Perhitungan Luas Cakupan}

Penelitian ini menggunakan bandwidth 15 $\mathrm{MHz}$ dan modulasi yang digunakan adalah QPSK, maka dari tabel 4.1. pada bab sebelumnya dapat diketahui bahwa nilai dari kapasitas sel-nya adalah sebesar 25,2 MHz.

Tabel 4.2. Penggunaan bandwidth dan modulasi pada perencanaan LTE

\begin{tabular}{|c|c|c|c|}
\hline \multirow{2}{*}{$\begin{array}{c}\text { Bandwidth } \\
(\mathrm{MHz})\end{array}$} & $\begin{array}{c}\text { QPSK } \\
(\mathrm{Mbps})\end{array}$ & $\begin{array}{c}16 \\
\text { QAM } \\
(\mathrm{Mbps})\end{array}$ & $\begin{array}{c}\text { 64QAM } \\
(\mathrm{Mbps})\end{array}$ \\
\hline 1,4 & 2,016 & 4,032 & 6,048 \\
\hline 3 & 5,04 & 10,08 & 15,12 \\
\hline 5 & 8,4 & 16,8 & 25,2 \\
\hline 10 & 16,8 & 33,6 & 50,4 \\
\hline 15 & 25,2 & 50,4 & 75,6 \\
\hline 20 & 33,6 & 67,2 & 100,8 \\
\hline
\end{tabular}


Dan nilai OBQ total telah diperhitungkan sebelumnya, yaitu mendapatkan nilai sebesar $3.344,096 \mathrm{kbps} / \mathrm{km}^{2}$.

$$
\begin{aligned}
& L=(\text { kapasitas sel } \times 3) / O B Q t o t a l \\
& L=(25.200 \times 3) / 3.344,096 \\
& L=22,607 \mathrm{~km}^{2}
\end{aligned}
$$

\section{Perhitungan Jumlah eNode B}

Perhitungan jumlah eNode $\mathrm{B}$ pada penelitian ini, seperti berikut:

Jumlah eNode $B=\frac{1327,6}{22,607}$

Jumlah eNode $B=58,725$ eNode $B$

Jumlah eNode $B \approx 59$ eNode $B$

Dari perhitungan diatas dapat dijelaskan bahwa perhitungan jumlah eNode $\mathrm{B}$ dihitung dengan menggunakan parameter luas area perencanaan dengan luas cakupan suatu sel. Daerah Banyumas memiliki luas $1.327,6 \mathrm{~km}^{2}$ dan dari perhitungan sebelumnya diketahui bahwa luas cakupan sel adalah seluas 22,607 $\mathrm{km}^{2}$. Sehingga akan didapat jumlah eNode B sebanyak 59 buah eNode B untuk dapat mencakup seluruh area Banyumas.

\section{Hasil Simulasi}

Gambar 4 mempresentasikan hubungan antara perubahan besar nilai coding rate terhadap besar nilai MAPL yang dihasilkan, dari grafik terlihat bahwa semakin besar nilai coding rate menghasilkan nilai MAPL yang semakin kecil.

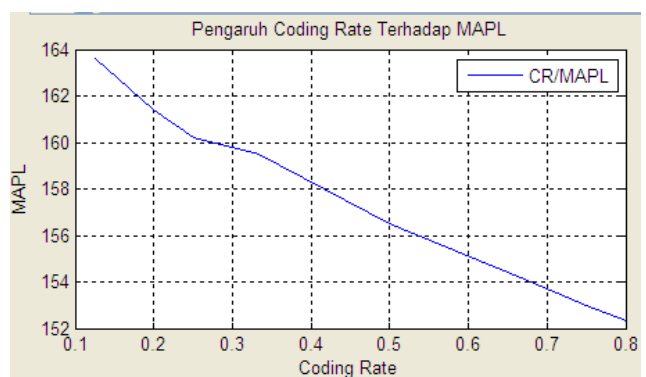

Gambar 4. Grafik hubungan Coding Rate terhadap MAPL

Contohnya yaitu pada coding rate 0,3 dihasilkan nilai MAPL dalam kisaran 160, lain halnya dengan nilai coding rate 0,7 yang menghasilkan MAPL dalam kisaran 154.

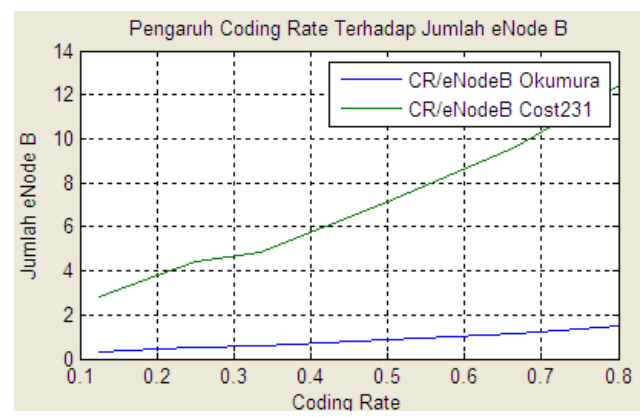

Gambar 5. Grafik hubungan Coding rate terhadap Jumlah eNode B

Gambar 5 adalah gambar grafik yang mempresentasikan mengenai hubungan perubahan besar nilai coding rate terhadap jumlah eNode B. Dari grafik tersebut terlihat bahwa semakin besarnya nilai coding rate yang digunakan maka jumlah eNode B yang dihasilkan semakin banyak. Hal ini dikarenakan nilai coding rate mempengaruhi nilai MAPL yang dihasilkan, sehingga semakin besar nilai coding rate maka semakin kecil nilai MAPL dan semakin kecil nilai MAPL maka semakin banyak jumlah eNode B yang dihasilkan. 


\section{KESIMPULAN}

1. Kesimpulan dari sisi perancangan melalui penghitungan berupa kapasitas dan coverage adalah sebagai berikut:

a. Maximum Allowable Path Loss (MAPL) pada perancangan cakupan area penelitian ini untuk arah downlink yaitu $154,474 \mathrm{~dB}$ dan untuk arah uplink yaitu sebesar 98,174 dB. Besarnya nilai daya sinyal yang diharapkan dapat diterima oleh UE adalah $97,174 \mathrm{~dB}$.

b. Prediksi jumlah pelanggan untuk lima tahun kedepan di daerah Banyumas adalah 43.886 pelanggan dengan faktor pertumbuhan penduduk sebesar $0,715 \%$.

c. OBQ total yang digunakan untuk perancangan cakupan area di Banyumas adalah 3.344,096 kbps/km² dengan asumsi pelanggan sebuah operator $40 \%$. OBQ total dipengaruhi oleh parameter kepadatan pelanggan, penetrasi pengguna tiap layanan, durasi panggilan efektif, busy hour call attempt, dan net user bit rate.

d. Kapasitas sel yang dihasilkan adalah 19,241 Mbps, dengan menggunakan modulasi QPSK dan coding rate $1 / 2$.

e. Luas cakupan sel dari perancangan cakupan area LTE di daerah Banyumas adalah 22,607 $\mathrm{km}^{2}$ dengan menggunakan 3 sektor yang memiliki jari-jari 2,11 km. Dan menghasilkan sebanyak 59 buah eNode B yang diperlukan untuk mencakup seluruh area Banyumas.

2. Kesimpulan dari sisi simulasi yang disimulasikan dengan software Matlab adalah sebagai berikut: a. Alat bantu hitung yang dibuat dengan menggunakan software Matlab, hasilnya hampir presisi dengan penghitungan manual parameter-parameter yang ada untuk sebuah perancangan cakupan area LTE di suatu daerah.

b. Dari grafik yang ada dapat disimpulkan bahwa perubahan besar nilai coding rate terhadap besar nilai MAPL yang dihasilkan.

c. Semakin besar nilai coding rate maka semakin banyak jumlah eNode B yang dihasilkan.

d. Semakin besar frekuensi yang digunakan maka semakin banyak jumlah eNode B yang harus digunakan.

\section{DAFTAR PUSTAKA}

1. Hikmaturokhman, Alfin. dkk. 2010. Tugas Broadband and Future Network Long Term Evolution (LTE). Bandung: IT Telkom.

2. Hikmaturokhman, Alfin. 2011. Diktat Kuliah Teknik Seluler.ppt. AKATEL Sandhy Putra Purwokerto.

3. Usma, Uke Kurniawan. dkk. 2012."Fundamental Teknologi Seluler LTE". Bandung: Rekayasa Sains.

4. Anonymous. 2009. "LTE RF Planning Guide". Motorola,Inc.

5. Abdul Basit, Syed. Tesis Dimensioning of LTE Network Description of Models and Tool, Coverage and Capacity Estimation of 3GPP Long Term Evolution radio interface. Helsinki: Helsinki University of Technology.2009.

6. Anonymous. "LTE Radio Frequency Planning". 
7. Holma, Harri. dan Antti Toskala. 2007. "WCDMA for UMTS - HSPA evolution and LTE 4th edition". USA: John Wiley \& Sons,Ltd.

8. Kottkamp, Meik. 2009. "LTE Advanced Technology Introduction Application Note". Rohde \& Schwarz.

9. Hikmaturokhman, Alfin. "Diktat Kuliah Wireless (Propagasi)". AKATEL Sandhy Putra Purwokerto. 2009.

10.Pangestu Maulita, Diah. "Perencanaan Coverage Area Femtocell di Gedung B Institut Teknologi Telkom". Bandung: Institut Teknologi Telkom. 2011.

11.Anonymous. [online] [Cited: April 4,2012] http://www.banyumaskab.go.id/banyu maskita/index.php?idm=\&jns=1\&id_b $\underline{\text { erita }=33}$.

12.Anonymous. [online] [Cited: 9 Juli 2012] http://tikometer.or.id
13.Paulus, Erik. dan Yessica
Nataliani.2007."Cepat Mahir GUI
Matlab".Yogyakarta: Andi Offset.. 